\title{
Da referência à abstração: um ensaio sobre o diagrama como ponto de inflexão no projeto arquitetônico
}

\author{
Henrique Carvalho Delarue \\ Arquiteto pelo Departamento de Arquitetura e Urbanismo da PUC-Rio \\ Contato: hcdelarue@gmail.com
}

\section{RESUMO}

Partindo do princípio que o diagrama funciona pela abstração e que, na maior parte das vezes, seu uso hoje em dia se limita a uma explicação, este ensaio explora alguns de seus aspectos que possibilitam seu uso como instrumento para o projeto arquitetônico. Fazendo uma breve análise de como a arquitetura carregava um valor simbólico oriundo da Antiguidade e como passou a ser vista de maneira abstrata, um paralelo é traçado entre modos de pensar a arquitetura e como a abstração se afasta da dependência da referência para construir um significado. Ao passo que a abstraçáo se intensifica, menos os elementos arquitetônicos carregam significado dentro de um sistema referencial e são vistos mais em função de como se relacionam. É considerando as relaçóes que podem ser absorvidas por uma arquitetura que o diagrama encontra seu potencial para anteceder a forma e reconfigurar como pensamos o processo de projeto.

Palavras-chave: simbólico, abstração, relações, diagrama, projeto

\section{ABSTRACT}

Starting from the principle that the diagram functions by abstraction and that, in most cases, its use today is limited to an explanation, this essay explores some of its aspects that make possible its use as an instrument for the architectural design project. By doing a brief analysis on how architecture used to take onto itself a symbolic value engendered in Antiquity and how it came to be seen in an abstract manner, a parallel is drawn between modes of thinking architecture and how abstraction moves away from the dependency of a reference to construct meaning. Whilst abstraction is intensified, architectural elements carry less meaning within a referential system and are seen more according to how they relate to each other. It is by considering the relations that can be absorbed by an architecture that the diagram finds its potential to precede form and reshape how we think the design process.

Keywords: symbolic, abstraction, relations, diagram, design project 


\section{Introdução}

Desde a segunda metade do século XX, o diagrama começou a ser incorporado com progressiva intensidade ao discurso teórico e prático da arquitetura, estabelecendo sua ubiquidade tanto no âmbito acadêmico quanto profissional. Sendo utilizado e incentivado como parte do projeto, muitas vezes é adotado como uma chave para comunicar de maneira simplificada uma ideia inicial, um grupo de dados, uma série de tomada de decisóes, um aspecto da proposta arquitetônica, entre outros fatores. Sua presença nas discussóes do ateliê de projeto, seja na forma de croquis iniciais, seja em pranchas de apresentação, se mostra desejável, porém, sua reflexão como instrumento de pensamento e produção é geralmente deixada de lado em favor de seu produto.

Neste ensaio, parto do princípio que o diagrama funciona pela abstração e proponho discutir sobre algumas de suas potencialidades como instrumento de projeto. Para tanto, especulo como a abstração afetou a maneira como pensamos a arquitetura em um contexto de transição do valor simbólico, como definido desde a Antiguidade, para a abstração, principalmente como promovida pelo Movimento Moderno. Tendo em mente a forte relação do simbólico com a imagem e como a abstração define um afastamento desta, é possível traçar um paralelo entre as mudanças que ocorreram em como nos aproximamos da arquitetura e dos métodos de projeto. Nesse contexto, o diagrama pode ser visto pela perspectiva de um desdobramento da percepção abstrata.

Mais do que uma maneira sintética de representar, o diagrama sugere (ou reflete) um outro modo de pensar. Dito isso, as questôes que podemos levantar são: que tipo de pensamento o diagrama implica? O que o diagrama seria capaz de oferecer além do desenho tradicional (projeçóes ortogonais e perspectivas) para o projeto? Que mudanças no pensamento conceptivo pode estimular? Afinal, como pode ser adotado como um instrumento de projeto?
Ao se tratar do processo de projeto, é relevante primeiro revisitar criticamente tal processo como o conhecemos. Apesar de muito parecer que a maneira como projetamos seja natural, e talvez até óbvia, a relação estabelecida entre a concepçáo e a representação em um contexto histórico-cultural de origem europia implica valores específicos ao projeto em si.

Durante o Renascimento, o desenvolvimento da escala e da perspectiva revolucionou a prática da arquitetura, e o desenho passou a ser tratado como o meio fundamental para o desenvolvimento, comunicação e construção do projeto arquitetônico. Sendo assim, o processo de projeto inevitavelmente se fez dependente de uma imagem prévia à qual faria referência e representaria. Isto é, o projeto como um todo se configurou de tal maneira que seu andamento em direção à edificação efetiva dependesse de uma imagem dessa própria edificação antes mesmo de sua existência.

$\mathrm{O}$ projeto, então, se inicia com uma imagem em direção a ela mesma, em um ciclo fechado onde a forma se faz presente tanto no início (ideia) quanto no resultado do projeto (edifício). A forma em sua definição fechada é o único fim pelo qual se justifica o meio. A representação faz referência à imagem mentalizada do projeto e quanto mais a forma desenhada reflete a forma imaginada, mais é valorizada ${ }^{1}$. Portanto, o sentido do desenho é dado ao ser lido pelo viés da mimese da forma.

A ênfase posta sobre o papel do desenho como a representação da ideia pode, então, ser considerada como um sintoma de uma cultura que sintetizou a problemática - e por consequência a solução — da arquitetura ao domínio de projeçóes, ou seja, a representação da forma. Consequentemente, a incapacidade de expressão gráfica inviabilizaria a prática. Decorrente disso, forjou-se uma equiparação da mistificada habilidade de representar à capacidade de pensar e projetar arquitetura. Até os dias de hoje, exames de habilidade são utilizados para adentrar universidades, como o chamado THE (Teste de Ha- 
bilidade Específica), e o desenho em sua beleza artística, ou por composiçóes formais na apresentação de pranchas de projetos, aparece como um fetiche.

\section{A Percepçáo da Abstraçáo na Arquitetura}

De uma maneira similar como o desenho teria que estar vinculado à forma para ter significado e ser útil, a arquitetura também teve seu valor histórico atribuído a sua construção como referência. Na Antiguidade, a arquitetura se fazia mimética pelas ordens clássicas: por espelharem a percepção do corpo humano e da natureza, as ordens atribuíam valor simbólico às edificaçôes (EISENMAN, 2008). Mesmo que só formalmente, essa relação foi herdada posteriormente pela linguagem dita "clássica" (de influência greco-romana), definindo a imagem da arquitetura pela referência até o Moderno (com algumas variaçóes temporais).

Ademais, havia um consentimento respaldado pelos livros de Vitrúvio de que a arquitetura imitaria edificaçóes primitivas feitas de madeira e pele de animais. Nesse contexto, por muitos séculos foi tida como "uma arte de imitação" (FORTY, 2004, p.224, tradução minha), como definida pela Encyclopédie de Denis Diderot e Jean le Rond d'Alembert em 1751. Portanto, a arquitetura não só copiaria princípios da natureza como também tais estruturas.

Para Peter Eisenman, a arquitetura não representa algo efetivamente, mas se convence a fazê-lo ao atribuir caráter simbólico a seus elementos. Assim, se aprisiona a uma simulação de modo que "sempre alude a — ou pretende representar — um outro objeto, seja ele arquitetural, antropomórfico, natural ou tecnológico" (EISENMAN, 2008, p.241). Com a retomada dos valores clássicos após o Medievo, passou a se definir como cópia de arquiteturas passadas e só seria reconhecida como verdadeiramente "Arquitetura" caso estivesse inserida numa linha evolutiva que começava na arquitetura clássica (EISENMAN, 2008, p.234).

A partir do final do século XVIII, a arquitetura iniciou um lento processo de tornar abstratos seus elementos, abandonando a relação mimética com o mundo para alcançar um universo geométrico. Jean-Nicolas-Louis Durand considerava os elementos arquitetônicos como formas e geometrias sem referência a algum objeto anterior, entendendo a coluna como um "cilindro de matéria” (PÉREZ-GÓMEZ, 1982, p.6, tradução minha). Assim, pode ser interpretada no discurso do arquiteto francês uma insinuação de uma compreensão abstrata da arquitetura, onde Le Corbusier viria a achar "uma arma contra os estilos históricos e um poderoso reforço para uma arquitetura baseada em forma (e suas qualidades de massa e superfície) e espaço (e suas qualidades de invólucro ou infinidade)" (VIDLER, 2000, p.11, tradução minha).

Em seu tempo, entretanto, Durand ainda recorria à chancela da linguagem clássica como a condição de existência da arquitetura, fazendo uso de colunas e elementos adornados. A arquitetura ainda estava vinculada à cópia, ou seja, sua substância dependia de uma referência imagética definida historicamente para se fazer existente.

Assim como sinalizado pela arte do final do século XIX, e em especial pelas vanguardas do início do século XX, a necessidade da referência para que uma obra fosse dotada de sentido foi superada para que

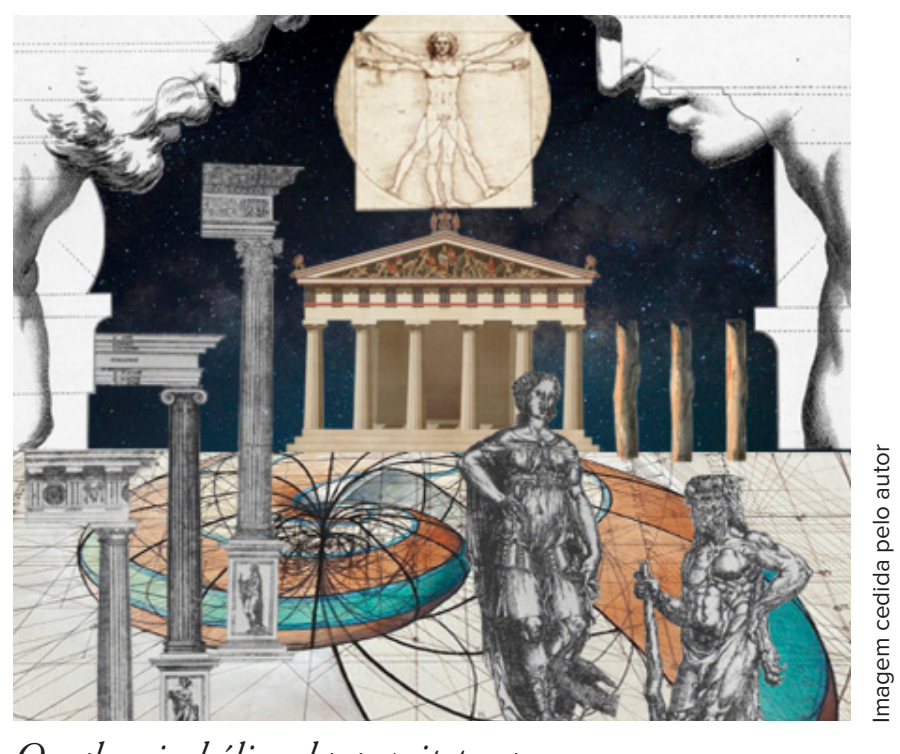

O valor simbólico da arquitetura. 
cada vez mais esta tivesse sentido em si mesma. $\mathrm{Na}$ arte, isso se deu formalmente por um processo de "empobrecimento da pintura" (BARR, 2003, p.30, tradução minha), ou seja, um afastamento da representação figurativa carregada de valor cultural. A abstração, então, se deu como "uma eliminaçáo de um amplo leque de valores, como as conotaçôes de tema [ou motivo]; sentimentais, documentários, políticos, sexuais, religiosos". Não havendo figuras reconhecíveis e mimetismos que tomassem o protagonismo, a obra em si se tornou "um fim em si mesma com seu próprio valor peculiar".

Por mais que a abstração tenha sido explorada de um ponto de vista reducionista e atrelada a uma ideologia pela arte e arquitetura no início do século XX, principalmente ao que se diz respeito à busca por uma linguagem pura e universal, isso aconteceu em um período em que o próprio mundo se fazia abstrato. Com as novas tecnologias, como os automóveis (1886), luzes elétricas (1880), ar condicionado (1902) e telefone (1876), ações ficaram descontextualizadas, mudando percepçóes de espaço e tempo. Não só os novos dispositivos substituíram funcionalmente a natureza como se declararam independentes desta, tornando o mundo livre de referências naturais. Por conseguinte, as obras abstratas se caracterizariam como "simplesmente a realidade do mundo abstrato" (HALLEY, 2013, p.142, tradução minha).

Eisenman reconhece o processo de abstração da $\mathrm{Ar}$ quitetura Moderna como um movimento para se afastar da necessidade de se referenciar a algo, e assim, se validar. Segundo ele,

A arquitetura moderna propôs-se corrigir e se libertar da ficção renascentista da representação, postulando que a arquitetura não tinha mais necessidade de representar uma outra arquitetura: ela devia apenas corporificar sua própria função. [...] Desse modo, no esforço para distanciar-se da antiga tradição representativa, a arquitetura moderna tentou despojar-se dos aparatos exteriores do estilo "clássico.” (EISENMAN, 2008, p.234)

A própria coluna (aqui já denominada pilar) passou a ser entendida como elemento abstrato. Como tal, por se redefinir sem referência imagética, pôde ser desassociada de suas conformaçóes clássicas e assumir novas, com seçôes retangulares, sem capitéis e com outros formatos.

As funções dos elementos e do próprio edifício superaram a sua imagem, isto é, o que viria a parecer. Ademais, a arquitetura passou a ser "livre de associaçôes culturais específicas e usava uma linguagem formal 'pura' que supostamente encantaria diretamente ao cérebro humano" (WESTON, 2011, p.143, tradução minha). Conformava-se nesses dois sentidos, então, como abstrata, almejando quebrar o padrão representativo pelo qual o significado dependia de uma referência histórica que faria sentido somente em uma determinada cultura. Assim sendo, uma arquitetura com caráter "universal" seria instaurada, podendo ser aplicada em vários lugares do mundo, dominada pelo intelecto, e caracterizada por "formas geométricas claras, superfícies brancas ou de cores simples, e o extenso uso de grandes lâminas de vidro".

No contexto da segunda metade do século XX, é importante mencionar o antagonismo notório ao método de produção da arquitetura que Eisenman configura, dando um passo adiante ao que tinha sido contemplado pela abstração anteriormente. Em seu estudo de casas geradas a partir de operaçóes sobre um cubo (entre os anos 1967 e 1978), propóe a abstração da arquitetura retirando qualquer significado dado a seus elementos (e à própria edificação) baseado em uma lógica arquitetônica existente. Questôes como o lugar, programa, função e sistemas construtivos para ele se tornam irrelevantes.

Eisenman recusa o simbólico para embarcar em uma pesquisa estritamente formal sobre a "linguagem arquitetônica como algo que se explica por si" 
(MONEO, 2008, p.139) - a forma se referencia a si mesma. O processo de projeto das casas é totalmente abstrato, acontecendo em um espaço intelectualizado por perspectivas de projeção paralela e com o auxílio de uma retícula imaginária. Não são casas que incorporam seu valor histórico de residências, tampouco a conotação de lar. O objeto não tem terreno, é alheio "a qualquer possível referência externa" (MONEO, 2008, p.141), e deveria ser imaculado de qualquer programa.

Enquanto no Moderno a articulação de elementos formais definidos funcionalmente com precisão era essencial para a arquitetura, Eisenman retira as funçóes dos elementos arquitetônicos (estruturais, de fechamento, e até escadas) e os define pelas operaçóes do processo, sendo qualificados ainda mais estritamente como elementos geométricos sem valor se não semântico. Sua forma é abstrata quanto a sua função. O pilar, por exemplo, não quer dizer mais "estrutura" impreterivelmente, podendo ser "o resultado da intersecçáo de dois planos ou do simples vazio que mantém a vigência da retícula" (MONEO, 2008, p.144), ou até mesmo ser um elemento isolado.

Com base nessa breve análise de como a abstração foi sendo adotada pelo discurso arquitetônico, entende-se que, ao longo desse processo, o afastamento de uma referência levou cada vez mais a uma possível autonomia da obra. Desse modo, possibilitaria a exploração de questóes da arquitetura que antes estavam contaminadas com um significado específico. Se na Antiguidade a existência dos elementos era determinada pela referência simbólica e, após o Medievo, histórica, no Moderno se fez geométrica e funcional até que no trabalho de Eisenman se tornou causal. Despidos de sua significância (tanto no sentido de relevância e de seu significado), os elementos poderiam ser cada vez mais vistos estritamente pela sua forma.

\section{A Abstração na Representaçáo}

Para além da percepçáo da forma, a matriz de pensamento abstrato, a qual possibilita a leitura de algo dentro de seu próprio sistema de elementos, é um mecanismo essencial para a representação e a execução de até as mais primitivas projeçôes ortogonais. Com o domínio da escala, o edifício foi reduzido às suas partes e seçóes representadas no desenho. Assim, a representação causou uma fratura entre o reconhecimento do objeto em sua totalidade e seu entendimento. Em outras palavras, a compreensão do edifício se deslocou do campo experiencial (físico) para o campo mental, fazendo com que a presença da pessoa junto à obra se tornasse dispensável ${ }^{2}$.

Ao contrário da presença física da própria obra em seu próprio contexto, é da natureza de qualquer representação que a informação seja condensada e adaptada para que seja comunicada (KALAY, 2004, p.87-88). É um procedimento necessário para que a representaçáo em questáo possa suportar a mensagem e se refira à edificação sem ser a réplica da mesma. O desenho, entáo, náo imita os elementos arquitetônicos, replicando-os literalmente, mas os re-apresenta como formas construídas por linhas. Uma vez que "a planta e a seção nunca podem de fato ser experienciadas" (PAI, 2002, p.56, tradução minha), são, então, aprisionadas a uma compreensão mental, abstrata.

Quanto mais informaçóes sobre a obra uma representação busca incluir, mais mimética é. Em contrapartida, quanto mais abstrata, menos constitui uma referência formal de simples compreensão e é mais aberta à interpretação por quem não tem o conhecimento para lê-la. Assim como um desenho técnico pode significar outras coisas que não seu objeto para uma pessoa leiga, um desenho muito abstrato pode ser usado tanto como uma planta quanto como um corte, ou até mesmo como um detalhe ou um plano piloto de uma cidade.

Ao retirar do desenho o rigor da referência à forma e suas conotaçóes geométricas, o significado deixa de ser explícito pelas convençóes que dáo sentido ao desenho tradicional e passa para o que pode ser extraído da lógica disposta pela própria figura. Como uma representaçáo que prioriza a relação das partes 


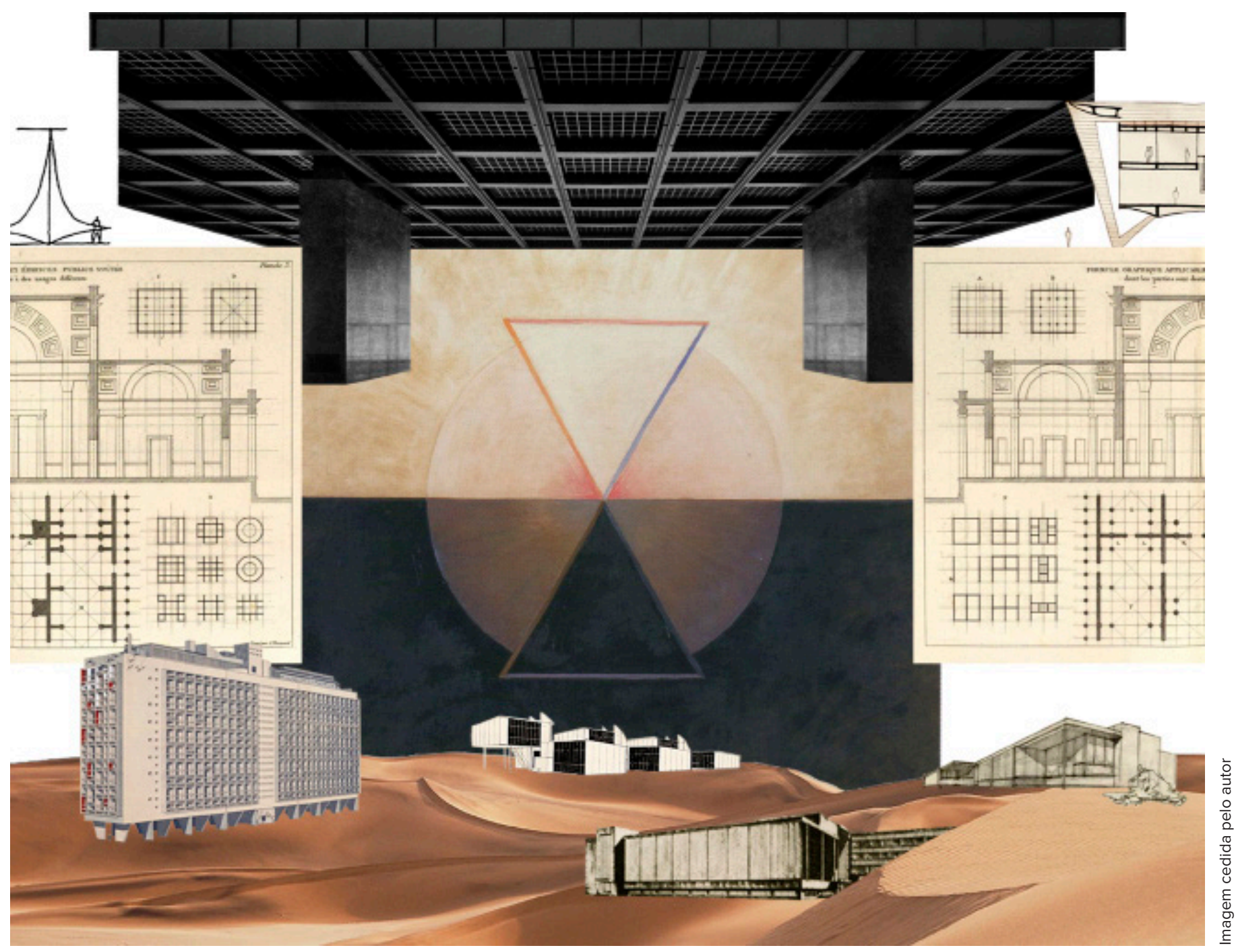

A abstração moderna.

à aparência do objeto em sua totalidade, o diagrama pode ser encontrado nessa lacuna criada pelo afastamento da referência. O diagrama não se encarrega de entregar um entendimento completo da obra, tampouco pode ser usado como instruçóes construtivas, mas cria e explicita relaçóes espaciais (SPERLING e ROSADO, 2014, p.572).

O diagrama é comumente visto como um recurso utilizado abundantemente com o objetivo de criar uma narrativa em torno de uma determinada forma, como que a justificar as decisóes projetuais. Nesse cenário, tem ocupado um espaço explicativo de com- plemento ao projeto, sendo encontrado no processo de desenvolvimento de um projeto, por exemplo, como notação de uma intenção (conceito), ou como um resumo do projeto finalizado ou da obra (desenho síntese), na forma de imagens explicativas.

No entanto, ao se pensar no diagrama somente como uma representação comprobatória de alguma decisão, esse se torna uma "coisa depois-de-um-fato, um dispositivo explanatório para comunicar ou clarificar forma, estrutura, ou programa” (ALLEN, 2009, p.50, tradução minha). Stan Allen afirma que tal visão, por conseguinte, "negligencia a capacidade ge- 


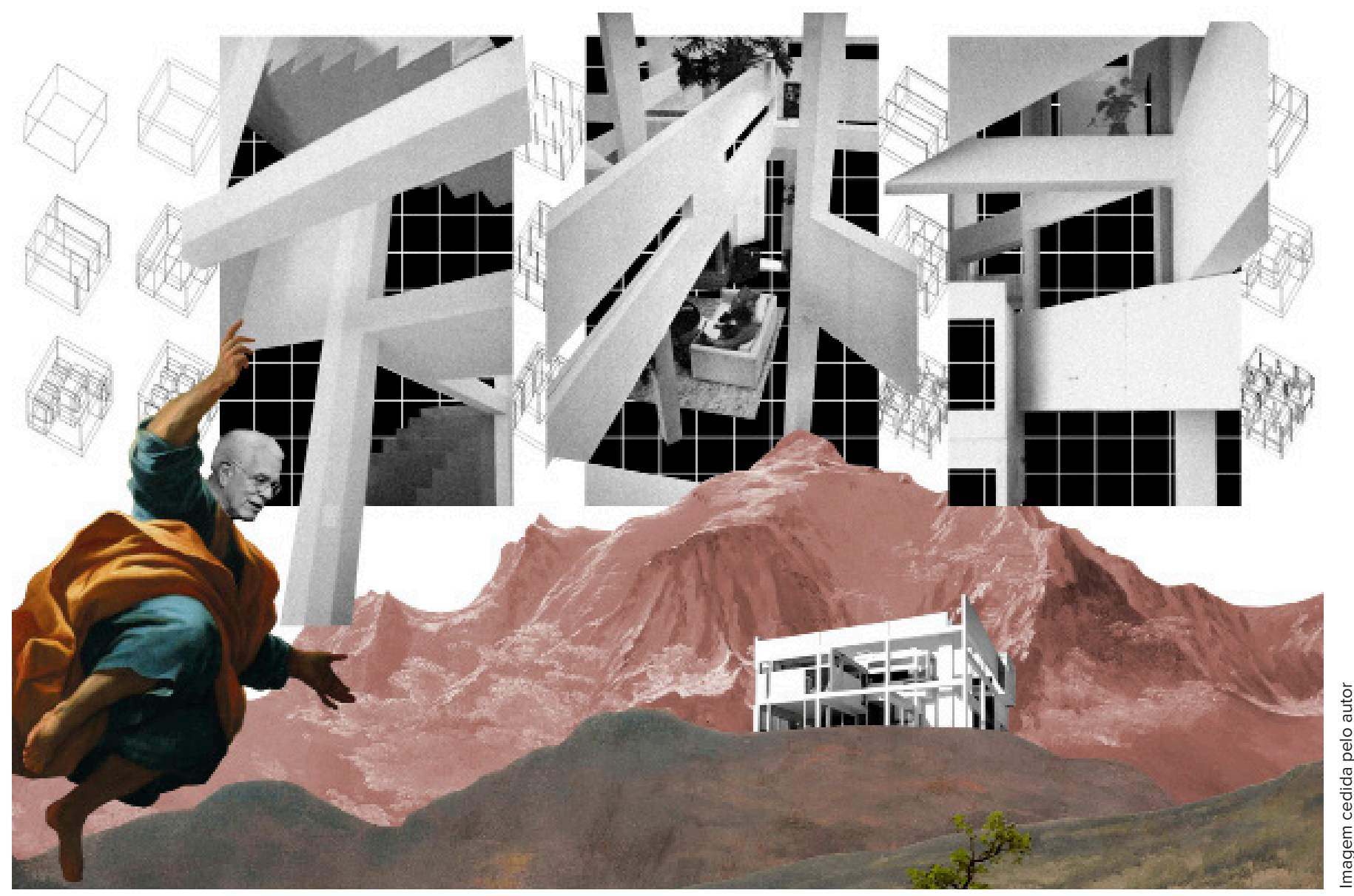

Abstração em Eisenman.

nerativa do diagrama”. Apesar de ser um dos seu usos possíveis, ao se caracterizar pela pós-produção, o diagrama é distanciado da ação do projeto (SPERLING e ROSADO, 2014, p.574). Distinguem-se, assim, dois campos principais para seu emprego: um ilustrativo e outro operativo.

Como decerto o diagrama ilustrativo depende da forma, e portanto é pictórico ${ }^{3}$, é seu modo operativo que pode ser especulado como parte da concepção do projeto arquitetônico. Estes diagramas se diferenciam principalmente dos ilustrativos por conterem relaçôes específicas que não usam a forma como base para serem demonstradas. Por um lado, a figura do diagrama é abstrata pois não representa seu objeto de maneira reconhecível, por outro lado, quanto no sentido representativo, o diagrama é abstrato pois se refere a características abstratas entre os elementos. As relaçóes entre partes náo se tratam das partes em si, como em uma representação mimética, mas o que as relaciona é uma característica abstrata - não depende de sua existência física apesar de estar presente em seu agrupamento.

Ao se desvirtuar do papel exclusivamente representativo de imagens específicas, o propósito do diagrama náo se encontra fixado em comunicar uma imagem e por isso, "não depende de o quão bem se sabe desenhar, ou o quão bonito é o produto" (TSCHUMI, 2014, p.6, tradução minha). O diagrama não tem um "propósito estético", catalisando o questionamento da imprescindibilidade de uma aptidão para o desenho como pré-requisito para a prática da arquitetura. 
Como apontado previamente, a lógica das representaçôes usadas ao longo do projeto é sujeita a ser representativa por depender de uma imagem já estipulada na mente e traduzi-la de um âmbito mental para uma conformação física. Contudo, o processo que decorre do diagrama se faz como uma proto-representação, pois não tem como objetivo traduzir uma forma já estabelecida, mas expóe uma ideia em formação (SCHEEREN e SPERLING, 2013, p.264). A ideia se desenvolve ao longo do projeto ao mesmo tempo que é posta de maneira gráfica, náo como um meio para chegar a um fim já conhecido, mas como um meio aberto que mostra outras possibilidades.

O diagrama não é sobre a disciplina histórica da arquitetura, não é canônico e seu processo não é definido pelos efeitos de sua aplicabilidade. Ao contrastar diagramas com sistemas de notação (como os desenhos arquitetônicos tradicionais), estes "operam de acordo com uma convenção compartilhada de interpretação", e esses são "sintáticos e não semânticos, mais concernidos com estrutura do que com significado" (ALLEN, 2009, p.50, tradução minha). Assim, são "abertos a múltiplas interpretaçôes", não são decifráveis de uma maneira pré-determinada e podem levar a diferentes direçóes dependendo de como são lidos.

\section{O Funcionamento dos Diagramas Operativos}

Projetos realizados que aderem à lógica do diagrama talvez possam ser identificados como "processos topológicos ${ }^{4}$ que investigam e representam relaçóes espaciais", ao contrário de "processos geométricos que investigam e representam as transformaçóes formais" (SPERLING, 2004, p.380-381, tradução minha). O diagrama, portanto, se mostra contrastante à lógica de representaçóes tradicionais, que se embasam na descrição da forma. No entanto, a diferença entre esses processos não se dá meramente pela hierarquia entre espaço e forma, mas pela própria definição de como o projeto se dá e se desenvolve.

O diagrama não se refere ao seu objeto, mas por ser uma expressão das relaçóes contidas neste, o substitui e toma seu lugar (VIDLER, 2006, p.21). Ou seja, o projeto arquitetônico momentaneamente se torna um projeto de relaçóes e não de um edifício propriamente dito. Por seu objeto de representação ser as relaçóes, o diagrama trabalha no campo da abstraçáo, pois precisa de um "corpo" para ser expressado e ganhar existência física. É uma operação que, pelas suas relações, tem efeitos além de si mesma mas sozinha não quer dizer nada. O diagrama se refere às estruturas implícitas de uma forma e se mostra ele mesmo.

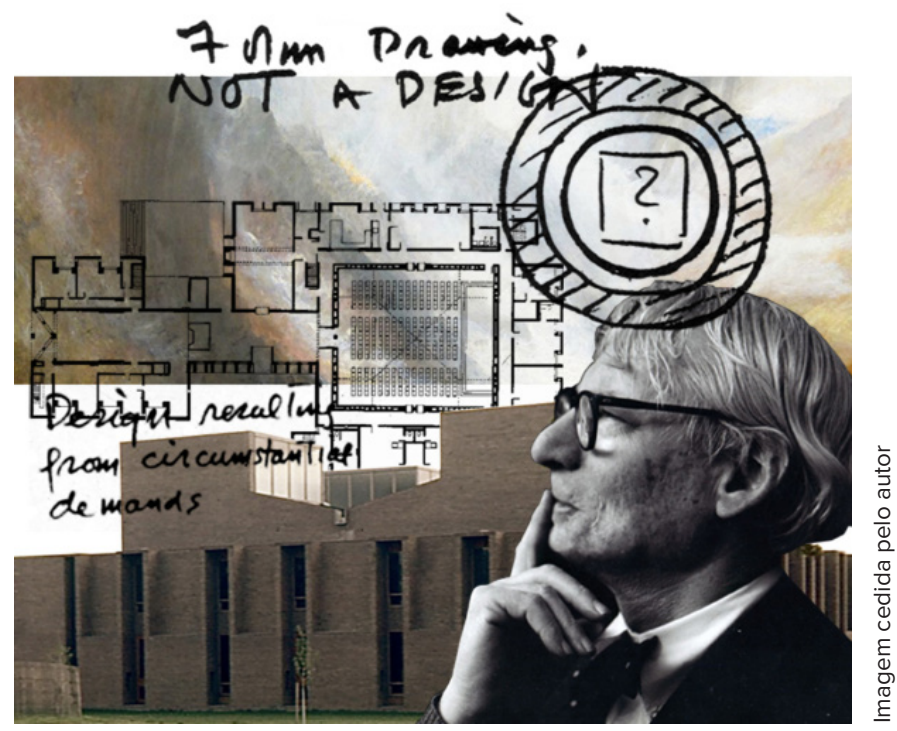

Diagrama em Kahn.

Para Gilles Deleuze, o diagrama é um "conjunto operatório das linhas e zonas, dos traços e manchas assignificantes e não representativos" (DELEUZE, 2007 , p.104), isto é, não carrega significado. Uma vez que não se prende a uma função representativa na arquitetura, não tem um significado codificado e referencial dentro de uma convenção, e, assim, requer um esforço interpretativo. Ademais, por não conter signos necessariamente pré-estabelecidos, não receita um significado pronto mas é sugestivo em um sentido de incitar algo que náo estava presente. Eisenman considera que "um diagrama está para a arquitetura como um texto está para uma narrativa" (EISENMAN, 2006, p.204, tradução minha), sendo assim, serve como embasamento para a criação da forma sem ser formal. 
$\mathrm{Na}$ arquitetura, a lógica do diagrama permeia o processo de projeto ao passo que "a intrusão persistente de signos e significados pode ser atrasada pelo diagrama, o qual entáo permite à arquitetura articular uma alternativa à técnica representativa de projeto" (BERKEL e BOS, 1998, p.23.21, tradução minha). Logo, o diagrama pode ser um veículo para novas ideias e novas lógicas para a arquitetura, afastando-se de respostas prontas. Além disso, o que é colocado em xeque pelo diagrama com esse movimento contra uma antecipação de significado é o processo que visualiza a forma final do projeto desde o início, sendo um meio para um fim já conhecido.

No processo de projeto diagramático que se aproxima da arquitetura pelas suas relaçóes, o diagrama se configura como "instrumento conceitual capaz de agir sobre si e modificar-se recursivamente" (SCHEEREN e SPERLING, 2013, p.263). Por mais que os desenhos arquitetônicos sejam passíveis de modificação, o que se modifica efetivamente é a estrutura formal. Bernard Tschumi descreve que projetar com base no desenho pode resultar em "petrificação", como, por exemplo o croqui, que "sugere algo que será seguido por uma versão mais elaborada do mesmo" (TSCHUMI, 2014, p.6, traduçáo minha) até chegar em um projeto executivo. O croqui, a perspectiva ou o desenho baseado na geometria descritiva se inserem no processo de projeto de maneira vinculada à elaboração da forma. No caso de um diagrama, por náo se tratar de uma representação de caráter definidor, manipulaçóes são instrumentais para gerar a forma subsequente ainda mantendo suas características específicas.

Com um ponto de vista otimista sobre o potencial dos diagramas, Tschumi os descreve como uma possibilidade para se afastar do pensamento formalista e funcional. Surgem como reflexo de realidades, ao invés de figuras geométricas idealizadas, e podem sugerir uma aproximação ao projeto que não exclusivamente sobre as funções que atende. Ademais, "são sobre um conjunto de disjunçóes dentre uso, forma, e valores sociais", e assim, conformam "a não coinci- dência entre significado e ser, movimento e espaço, ser humano e objeto" como a condição inicial para o trabalho. Além disso, o diagrama pode ser sobre "coisas normalmente removidas em representações arquitetônicas convencionais, a nomear a relação complexa entre espaços e seu uso; [...] entre objetos e eventos" (TSCHUMI, 1994, p.7, tradução minha).

O mais importante no diagrama, como já indicado, não é a sua figura, mas o que pode ser feito a partir dela. Tendo em vista o discurso da abstração na arquitetura e como se aplica no campo da representação, três características principais da abstração podem ser atribuídas como qualificadoras do diagrama como gênero de representaçáo e que o distinguem de outros: a independência do desenho em relação à forma final - a forma não precisa seguir a figura do diagrama; não correspondência direta a elementos construtivos - o que é desenhado não necessariamente é um elemento construído; representação de relaçóes imateriais - algumas das relaçóes que podem ser abordadas pelo diagrama podem ser movimento, usos, açôes, espaço, dinâmicas, proporções, sensaçôes, fatores naturais e relaçóes lógicas.

Uma possível aplicação do diagrama como origem do projeto foi sinalizada por Toyo Ito ao advogar por uma arquitetura-diagrama, pela qual o edifício "é em última instância equivalente ao diagrama do espaço usado para descrever abstratamente as atividades mundanas pressupostas pela estrutura" (ITO, 1996, p.18, tradução minha) $)^{5}$. Para Ito, a arquitetura-diagrama não tem origem na forma (ideológica ou estética), mas é um produto decorrente de uma organização diagramática que é evolutiva porém interrompida em determinado momento. A forma do edifício, então, não é compositiva, como um objeto delineado que deve ser aprimorado e detalhado, mas uma instância de seu diagrama.

Para além da descrição de Ito, Allen interpreta que "uma arquitetura-diagrama não é necessariamente uma arquitetura produzida por diagramas", mas uma que 
se comporta como um diagrama, indiferente aos meios específicos de sua realização. É uma arquitetura que estabelece uma adequação solta de programa e forma, um campo direcionado dentro do qual atividades múltiplas se desdobram, canalizadas mas não limitadas pelo envelope arquitetônico. (ALLEN, 1998, p.23.18, tradução minha)

Tendo em vista as práticas contemporâneas que fazem alusão ao diagrama, muitas vezes tal recurso gráfico náo parece ser usado seguindo suas potencialidades operativas como aqui apresentadas, limitando-se a "orientaçóes compositivas estilizadas" (PICON, 2010, p.82, tradução minha). Pela ótica deste ensaio, realizar um projeto fundamentado em diagramas náo significa começar o processo criativo por uma determinaçáo de forma, mas é processual e evolutivo. Mesmo que um diagrama esteja funcionando como em uma projeção ortogonal ou perspectiva, deve-se entender que não há conformação do projeto nessa etapa.

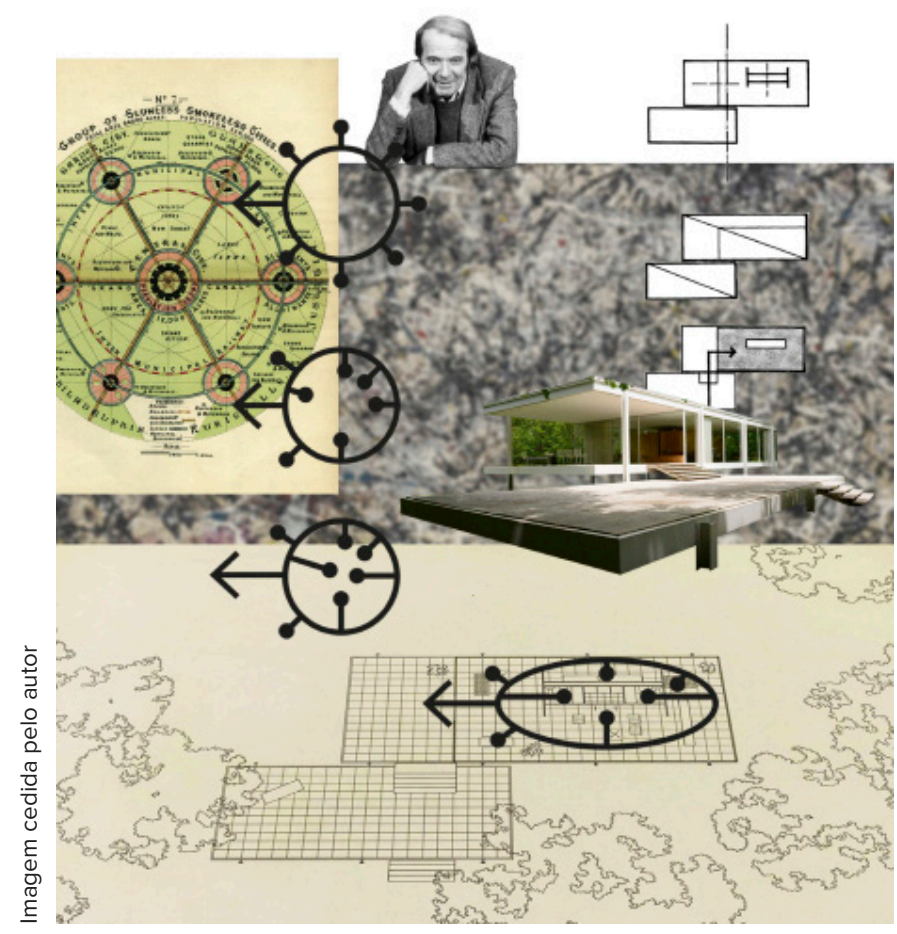

Aplicação do diagrama na casa Farnsworth.
Trabalhar com o diagrama é abrir oportunidade para uma alternativa de desenvolvimento projetual que não é vinculado estritamente à forma e suas condições físicas, como paredes, dimensôes e acessibilidade. É iniciar com o pensamento abstrato, pensar pelo viés de intençôes relacionais e não da forma, e trabalhar em um campo indefinido. Portanto, uma prática diagramática tampouco se garante só pelo desenho de diagramas. Para se consolidar, a própria matriz de pensamento da arquitetura precisa se voltar da forma para o diagrama ${ }^{6}$.

\section{Conclusão}

No processo de projeto, o diagrama deu um passo além da percepção abstrata pela arquitetura. Ao invés de se aproximar simbolicamente, funcionalmente ou até formalmente, o diagrama estipula relações que podem ser aplicadas em um projeto como um todo ou em uma parte. Seu grafismo é uma representação das relaçốes e não da arquitetura, e portanto prioriza termos genéricos a uma aplicação específica, como "ponto de convergência", "percurso", "limite", "acessos", "atividade" etc.

A dinâmica estabelecida pelo desenho tradicional que se remete à forma é revista pelo diagrama uma vez que o desenho tem o papel de traduzir a imagem mental para ser compreendida, e por isso precisa se manter fiel a mesma, e o diagrama é independente de tal imagem. Por não ser um código convencionado, são as relaçôes internas que são "movidas parte por parte do material gráfico ao material espacial, por meio de operaçóes que são sempre parciais, arbitrárias, e incompletas" (ALLEN, 1998, p.23.17, tradução minha).

Segundo Friedrich A. Kittler, "enquanto tradução exclui todos os detalhes em favor de um equivalente geral", a transposição "não pode apelar a nada universal e deve portanto deixar lacunas" (KITTLER apud ALLEN, 1998, p.23.17, tradução minha). Ao passo que a tradução da ideia para o desenho e do desenho ao edifício se responsabiliza a manter uma integridade total, a transposição se dá em relação às partes. 
Pela descrição de Kittler, entende-se que o diagrama seria uma transposição pelo seu caráter abstrato, que não intenciona estabelecer uma relação mimética. $\mathrm{A}$ partir disso, ao comparar a abstração do diagrama com a artística, o diagrama estaria muito mais próximo de um Expressionismo Abstrato do pós-guerra, incerta e subjetiva, do que uma abstração como almejada pelas vanguardas, precisa e intelectual.

Pelo caráter interpretativo e aberto do diagrama, uma prática diagramática náo pode ser configurada como uma técnica, mas como um processo, pois "é um tipo de pesquisa, um tipo de exploração, [e] só é técnica se entendermos que certo tipo de processo produz certos tipos de efeitos seguramente" (KIPNIS apud NOBRE, 1999, p.45, tradução minha). Para se manter diagramática e aberta, a prática deve ser imprevisível. Uma técnica (como a do desenho), ao "incorporar efeitos a priori", implica em "bloquear os movimentos de desterritorialização que a máquina abstrata [...] assume" (NOBRE, 1999, p.46, tradução minha). Já "uma técnica representativa implica que [...] fixemos a relação entre ideia e forma, entre conteúdo e estrutura” (BERKEL e BOS, 1998, p.23.21, tradução minha), fazendo com que um tipo se defina. Sendo assim, "esse é o problema com uma arquitetura que é baseada em um conceito representativo; não pode escapar a tipologias existentes".

Eisenman (2004, p.171) vê o processo projetual Moderno como nada mais que uma continuidade de como se fez concebido desde a Antiguidade, engendrando significado por uma ideia de perfeição e se referindo a formas de tipos simples. Pela lógica da composição, a edificação, cujo significado seria inerente a sua existência, tem o início de seu projeto a partir de um ponto zero bem definido, uma forma-tipo, e o processo decorrente é compreendido como vetores que desenvolvem o projeto a partir desse ponto. Em contraste, Eisenman defende que na decomposição não há um ponto inicial, pois não há uma forma ideal, tornando-se terreno fértil para o acolhimento dos diagramas como aqui explorados.
No processo de decomposição, revelam-se relaçóes inerentes antes ocultas por um olhar clássico e reverte-se a ideia de um processo conceptivo com início e fim para "um fim que é imanente dentro do novo objeto/processo" (EISENMAN, 2004, p.186, traduçáo minha). Ao aderir a uma ideia de projeto como processo, pelo qual e no qual a arquitetura é conformada, o diagrama talvez possa achar sua aplicação dentro da conotação da arquitetura como uma de suas múltiplas instâncias. Ao entender o projeto como um processo, abre-se espaço para a percepção de que a forma não é um fim absoluto a ser alcançado, deslocando seu protagonismo.

No campo da representaçáo, enquanto o desenho tradicional produz planos que são uma "notação literal" e "uma condição de escrita finita" (EISENMAN, 1998, p.23.28, traduçáo minha) — ou seja, se submetem a certos códigos pré-determinados para ganhar forma e significado e têm uma existência destinada a se remeter a um objeto como é —, o diagrama não impóe regras se não as suas próprias (características relacionais). No contexto do processo projetual conceptivo, pelo qual a leitura da arquitetura se faz sobre suas relaçóes, o ato de projetar é ressignificado para relacionar, ou seja, diagramar (SOUZA, 2010, p.130). Por essa perspectiva, o trabalho sobre o diagrama já é um feito arquitetônico.

\section{Notas de fim:}

1. Tal maneira de pensar era essencial para a Escola de Belas-Artes, principalmente em seu contexto ao longo do século XIX. No entanto, é indispensável lembrar que nossa educação arquitetônica contemporânea em maior parte é sua herdeira. Não coincidentemente, o "traçado genial" de praticantes veio a ser romantizado, como exemplificado frequentemente por Oscar Niemeyer.

2. Tal deslocamento aconteceu simultaneamente ao que Mario Carpo (2008, p.131) define como o "paradigma Albertiano", no qual se estabeleceria a consciência da se- 
paração entre o desenho conceptivo e a construção. Por conseguinte, a prática da arquitetura iniciou um gradual processo de afastamento do canteiro de obras e passou a ser reconhecida como uma prática intelectual.

3. Exemplos desse tipo de diagrama podem ser facilmente encontrados junto a desenhos técnicos e fotografias das obras arquitetônicas mais conhecidas das últimas décadas, e em especial nos projetos dos escritórios BIG, MVRDV, REX, JDS, entre outros.

4. "Topologia" é definida por Sperling (2003 apud SPERLING e ROSADO, 2014, p.573) "como um campo da matemática que estuda as relaçóes espaciais invariantes independentes de variaçóes formais". No contexto dos diagramas na arquitetura, isso quer dizer que os diagramas propóem estruturas implícitas que atendem a mais de uma forma sem alterar as relaçóes básicas estipuladas.

5. Ito usa como exemplo de uma arquitetura-diagrama o projeto de Kazuyo Sejima Dormitório de Mulheres Saishunkan Seiyaku (1990-1991), em Kumamoto, Japão.

6. Em outubro de 2019, tive a oportunidade de, junto com a professora Verônica Natividade, testar as noçôes discutidas aqui em sala de aula como parte da disciplina Fundamentos da Linguagem Visual na PUC-Rio. O exercício foi estruturado em duas etapas principais: a derivação de um diagrama a partir de uma imagem existente e uma proposição fundamentada no diagrama executado. Não só foi possível comprovar que diferentes conformaçôes podem dividir o mesmo diagrama como também que iniciar um projeto pelo diagrama pode impulsionar resultados que não seriam evidentes de antemão - como também em lugares e locais de infraestruturas (pontes, sistemas de esgoto e drenagem, entre outros) de difícil acesso, definidos pelo termo: 'off-limits'.

14. LINSAY, Taylor. Life after Tacheles: What's become of the artist squatters? (2018). Disponível em: < http://www. exberliner.com/features/culture/life-after-tacheles/>. Acesso em: 22 mar. 2019.

\section{Referências Bibliográficas}

ALLEN, Stan. Diagrams matter. ANY: Architecture New York, New York, n. 23, p. 23.16-23.19, 1998. Edição especial: Diagram work. Disponível em: <https://www. jstor.org/stable/i40087754>. Acesso em: 23 nov. 2018.

Practice: architecture, technique and representation. 2nd ed. Abingdon: Routledge, 2009. Originalmente publicado em 2000.

BARR, Alfred H. Cubism and abstract art. In: LIND, Maria (Ed.). Abstraction. London: Whitechapel Gallery, 2013, p. 28-33. (Coleçâo Documents of Contemporary Art). Originalmente publicado em 1936.

BERKEL, Ben van; BOS, Caroline. Diagrams: interactive instruments in operation. ANY: Architecture New York, New York, n. 23, p. 23.19-23.23, 1998. Edição especial: Diagram work. Disponível em: <https://www.jstor.org/ stable/i40087754>. Acesso em: 23 nov. 2018.

CARPO, Mario. Nonstandard morality: digital technology and its discontents. In: VIDLER, Anthony (Ed.). Architecture between spectacle and use. New Haven: Yale University Press, 2008, p. 127-142.

DELEUZE, Gilles. Francis Bacon: lógica da sensação. Tradução Roberto Machado, Aurélio G. Neto, Bruno L. Resende, Ovídio de Abreu, Paulo G. de Albuquerque, Tiago S. Themudo. Rio de Janeiro: Jorge Zahar, 2007. Originalmente publicado em 1981.

EISENMAN, Peter. Diagram: an original scene of writing. ANY: Architecture New York, New York, n. 23, p. 23.2723.29, 1998. Edição especial: Diagram work. Disponível em: <https://www.jstor.org/stable/i40087754>. Acesso em: 23 nov. 2018.

The futility of objects: decomposition and the processes of differentiation. In: Eisenman inside out: selected writings, 1963-1988. New Haven: Yale University Press, 2004, p. 169-188.

Feints: The diagram. In: CASSARÀ, Silvio (Ed.). Peter Eisenman: feints. Milan: Skira, 2006, p. 203-205. . O fim do clássico: o fim do começo, o fim do fim. In: NESBITT, Kate (Org.). Uma nova agenda para a ar- 
quitetura. Tradução Vera Pereira. 2. ed. São Paulo: Cosac Naify, 2008, p. 232-252. (Coleção Face Norte). Originalmente publicado em 1984 .

FORTY, Adrian. Words and buildings: a vocabulary of modern architecture. Edição em brochura. London: Thames \& Hudson, 2004. Originalmente publicado em 2000.

HALLEY, Peter. Abstraction and culture. In: LIND, Maria (Ed.). Abstraction. London: Whitechapel Gallery, 2013, p. 137-142. (Coleção Documents of Contemporary Art). Originalmente publicado em 1991.

ITO, Toyo. Diagram architecture. El Croquis, v. 77, n. 1, p. 18-24, 1996.

KALAY, Yehuda E. Architecture's new media: principles, theories, and methods of computer-aided design. Cambridge: MIT Press, 2004.

MONEO, Rafael. Peter Eisenman. In: Inquietação teórica e estratégia projetual na obra de oito arquitetos contemporâneos. Tradução Flávio Coddou. São Paulo: Cosac Naify, 2008, p. 135-182. (Coleção Face Norte).

NOBRE, Lígia. Diagrams and diagrammatic practice: on design process in the DRL (AA) 1997-98. 1999. Dissertação (Mestrado) - Architectural Association, Londres, 1999. Disponível em: <http://ligianobre.org/index.php/textos/diagrams-and-diagrammatic-practice/>. Acesso em: 23 nov. 2018.

PAI, Hyungmin. The portfolio and the diagram: architecture, discourse, and modernity in America. Cambridge: MIT Press, 2002.

PÉREZ-GÓMES, Alberto. Architecture as drawing. Journal of Architectural Education, v. 36, n. 2, p. 2-7, inverno 1982. Disponível em: <https://www.jstor.org/stable/1424613>. Acesso em: 20 set. 2018.

PICON, Antoine. Digital culture in architecture. Basel: Birkhäuser Architecture, 2010.
SCHEEREN, Rodrigo; SPERLING, David. Dos Diagramas aos Parâmetros: Transformaçōes no Design Digital. In: CONGRESSO SIGRADI, 17., 2013, Valparaiso. Knowledge-based design: proceedings of the 17th Conference of the Iberoamerican Society of Digital Graphics. 2013, p. 262-265. Disponível em: <https://www.researchgate. net/publication/270216689_Dos_Diagramas_aos_Parametros_Transformacoes_no_Design_Digital>. Acesso em: 26 nov. 2018.

SOUZA, Douglas de. A Configuração do Discurso do Diagrama na Arquitetura Contemporânea. 2010. Dissertação (Mestrado em Arquitetura e Urbanismo) - Faculdade de Arquitetura e Urbanismo, Universidade de São Paulo, São Paulo, 2010. Disponível em: <http://www.teses.usp. br/teses/disponiveis/16/16134/tde-16062010-112842/ pt-br.php>. Acesso em: 23 nov. 2018.

SPERLING, David. Architecture as a Digital Diagram. International Journal of Architectural Computing, v. 2, n. 3, p. 371-387, sep. 2004. Disponível em: <https:// www.researchgate.net/publication/30875242_Architecture_as_a_Digital_Diagram>. Acesso em: 28 out. 2018.

SPERLING, David; ROSADO, Camila. Diagrama: Entre Projeto e Comunicação - o Caso BIG. In: CONGRESSO SIGRADI, 18., 2014, Montevideo. SIGraDi 2014: Design in freedom; XVIII Congreso de la Sociedad Iberoamericana de Gráfica Digital. Montevideo: Blucher Design Proceedings, v. 1, n.8, p. 572-576, dez. 2014. Disponível em: <https://www.proceedings.blucher.com. br/article-list/sigradi2014-242/list\#articles $>$. Acesso em: 11 out. 2018 .

TSCHUMI, Bernard. The Manhattan transcripts. London: Academy Editions, 1994.

Notations. Diagrams \& sequences. London: Artifice, 2014.

VIDLER, Anthony. Diagrams of diagrams: architectural abstraction and modern representation. Representations, $\mathrm{v}$. 
72, p. 1-20, outono 2000. Disponível em: <https://www. jstor.org/stable/2902906>. Acesso em: 3 ago. 2018.

What is a diagram anyway? In: CASSARÀ, Silvio (Ed.). Peter Eisenman: feints. Milan: Skira, 2006, p. $18-27$.

WESTON, Richard. 100 Ideas that changed architecture.

London: Laurence King Publishing, 2011.

Revista online do Departamento de Arquitetura e Urbanismo da Pontifícia Universidade Católica Puc-Rio - Rio de Janeiro Brasil

Ano $5-N^{\circ} 8-$ ISSN $2446-7340$ 